\title{
A SMALL OUTBREAK OF NEONATAL MENINGITIS IN A MATERNITY UNIT
}

\author{
BY \\ ERIC MCKAY and JOHN SMITH \\ From the Royal Aberdeen Hospital for Sick Children and the Aberdeen City Hospital
}

(RECEIVED FOR PUBLICATION JANUARY 1, 1958)

The enterobacteriaceae are of particular importance in infancy as a cause of meningitis. Cooke and Bell (1922) postulated that certain strains of the coli aerogenes group might have a special tendency to invade the meninges, and suggested that full descriptions of the organisms isolated from such cases would be of value. Again, Barrett, Rammelkamp and Worcester (1942) commented on the frequent lack of sufficient detail for accurate classification of the organisms obtained in the majority of cases. Henderson (1948), in his review of Salmonella meningitis, found that a few types of salmonellae account for the majority of cases, and he also noted that three epidemics among the newborn accounted for more than one fourth of the 147 cases he had collected. A small outbreak of three cases of meningitis occurring in a maternity hospital is described, the organism being a hitherto unidentified member of the enterobacteriaceae.

\section{Case Histories}

Each of the three cases was accommodated for a few days at 'E' Maternity Hospital, Case 1 from July 2-8, 1957, and Cases 2 and 3 from August 22-28, 1957. During this period no other babies and, as far as can be ascertained, no members of staff or patients suffered from gastro-intestinal symptoms or other infections.

Case 1. K.L., a make infant of birth weight $7 \mathrm{lb} .8 \frac{1}{2} \mathrm{oz}$, was born by normal delivery at ' $E$ ' Maternity Hospital on July 2, 1957. He was the ninth child of healthy parents, the other children all being alive and well. The maternal membranes had ruptured immediately before the delivery, and the mother had no symptoms of urinary, gastro-intestinal or other infection. The infant was fed on evaporated milk, taking the feeds well and behaving normally until the age of 6 days when he became drowsy and refused to suck. Four hours later, when he had a brief episode of generalized twitching, the fontanelle was bulging slightly, the head was retracted, and the rectal temperature was $101^{\circ} \mathrm{F}$. The baby was transferred to Aberdeen City Hospital where lumbar puncture produced a purulent, blood-stained cerebrospinal fluid. The detailed bacteriology of cerebrospinal fluid and faeces is given below. Treatment was commenced with intramuscular penicillin and streptomycin but the infant died 14 hours after admission. The positive findings at autopsy were marked congestion of the meninges, a purulent exudate over the base of the brain and bilateral adrenal haemorrhage.

Cases 2 and 3. C.F. and R.F. were twins, born five weeks prematurely at 'A' Maternity Hospital on August 18, 1957; they were transferred to ' $E$ ' Maternity Hospital on August 22 and discharged home on August 28. R.F., twin 1 , was born by spontaneous vertex delivery, weighing $6 \mathrm{lb} .9 \mathrm{oz}$, and C.F., twin 2, by assisted breech delivery, weighing $5 \mathrm{lb} .12 \mathrm{oz}$. The maternal membranes ruptured only 45 minutes before delivery, and the mother had no fever or evidence of urinary or gastro-intestinal infection.

Case 2, C.F., was admitted to the Royal Aberdeen Hospital for Sick Children at the age of 12 days with a history of vomiting once 24 hours before admission with refusal to feed thereafter. On examination he was a drowsy hypotonic infant weighing $6 \mathrm{lb} .3 \frac{1}{2} \mathrm{oz}$., who did not appear acutely ill, but who had an intermittent slight cyanosis of the lips and peri-oral region. The rectal temperature was $98 \cdot 2^{\circ} \mathrm{F}$., pulse rate 146 per minute and respirations 58 per minute. A moderate degree of jaundice was present. No evidence was found of meningeal irritation or neurological abnormality and physical examination was otherwise negative. The urine contained a small amount of a reducing substance. The cerebrospinal fluid, which was under normal pressure, was greenish-yellow and turbid, containing 1,254 leucocytes $(66 \%$ polymorphonuclear) per c.mm. Numerous Gram-negative bacilli could be seen on film; details of the bacteriology of cerebrospinal fluid and faeces are given below.

Treatment And Progress. Treatment initially was by intramuscular chloramphenicol $(500 \mathrm{mg}$. daily for 29 days) and intramuscular streptomycin $(120 \mathrm{mg}$. daily for 32 days). Cortisone was given by the same route in decreasing dosage for the first two weeks commencing with $100 \mathrm{mg}$. daily; this was used in view of the experience with Case 1 and also in an unsuccessful attempt to prevent the adhesions so frequently seen in coliform meningitis. Convulsions during the first few days of the illness were 
controlled by intramuscular paraldehyde. Continuous oxygen therapy was required for the first 11 days and parenteral fluids for 12 days. At the end of the third week exploration of the left lateral ventricle revealed thick creamy pus which was aspirated daily with instillation of $25 \mathrm{mg}$. streptomycin on each occasion for the next 10 days. The infant remained extremely ill, vomiting frequently and gradually losing weight, and for this reason the therapy was changed, chloramphenicol being replaced by sulphadiazine $(0.75 \mathrm{~g}$. daily for nine weeks) and streptomycin by polymyxin B (intrathecally 20,000 units twice per day for three days and once per day for a further nine days, and intramuscularly 25,000 units fourhourly for three days, then six-hourly for nine days). During his sixth week in the ward the vomiting ceased and his weight began to rise, but at the age of four months he is markedly retarded in his motor development. Ventriculography shows a gross degree of internal hydrocephalus of obstructive type, although the head measurements are not increasing rapidly.

The causative organism was not cultured from the cerebrospinal fluid after the initial specimen, but a Gramnegative organism was seen on direct film as late as the end of the polymyxin treatment.

Case 3, R.F., was admitted to the Royal Aberdeen Hospital for Sick Children two days after his twin brother. This twin had remained well until only four hours before admission, when his mother noticed intermittent peri-oral cyanosis. He refused part of a feed and whimpered frequently. Following her experience with the first twin, the mother sought immediate medical attention. Physical examination at the time of admission showed a mildly jaundiced, fairly healthy-looking baby of $6 \mathrm{lb} .4 \frac{1}{2} \mathrm{oz}$. No cyanosis was present, the fontanelle was not bulging, and there was no rigidity of the spine or head retraction. The tone of the legs was considered to be slightly increased, and the cry was rather shrill. The cerebrospinal fluid was turbid, greenish-yellow, containing 54,000 leucocytes (91\% polymorphonuclear) per c.mm. The cerebrospinal protein was $280 \mathrm{mg}$. per $100 \mathrm{ml}$.; sugar, $15 \mathrm{mg}$. per $100 \mathrm{ml}$.; and chlorides, $710 \mathrm{mg}$. $\mathrm{NaCl}$ per $100 \mathrm{ml}$. Bacteriological details of cerebrospinal fluid and faeces are given below.

Treatment and Progress. Three short courses (14 days, 10 days, 10 days) were given of chloramphenicol and streptomycin with intervals of 14 days and eight days without antibiotics. The chloramphenicol was given intramuscularly (250 mg. twice daily) for the first course and orally ( $250 \mathrm{mg}$. six-hourly) for the two later courses. Streptomycin dosage was $120 \mathrm{mg}$. per day. Following these drugs oral sulphadiazine was administered for six weeks. Cortisone in decreasing dosage, commencing with $100 \mathrm{mg}$. daily, was also administered for the first 10 days. The illness of this twin ran a more benign course than in C.F. During the first few days in hospital signs of meningeal irritation developed; there were some brief episodes of twitching and also several mild cyanotic attacks, but bottle-feeding was possible throughout. The second and third courses of antibiotics were given because of recurrence of vomiting and irritability with increased numbers of pus cells in the cerebrospinal fluid although the causative organism was not cultured again. Subdural taps were negative four weeks after the onset of the illness. The present mental state of the child at the age of 4 months is difficult to assess but the general impression is unfavourable; he holds his head up with difficulty and is taking little notice of his environment.

\section{Bacteriological Investigation}

When it was found that the meningeal infection in the first case was due to an intestinal type of non-lactose fermenting organism, the faeces of the patient were examined and a similar organism was isolated. The strains obtained from the cerebrospinal fluid and from the faeces were next subjected to detailed fermentation and biochemical tests but no serological tests were carried out at this time. When the second and third cases of meningitis occurred some seven weeks later in patients from the same hospital the strains isolated from the cerebrospinal fluids and faeces were again tested for their full fermentation and biochemical activities. The reactions of the three strains isolated from the cerebrospinal fluids are given in Table 1. Similar tests applied

TABLE 1

BIOCHEMICAL AND FERMENTATION REACTIONS

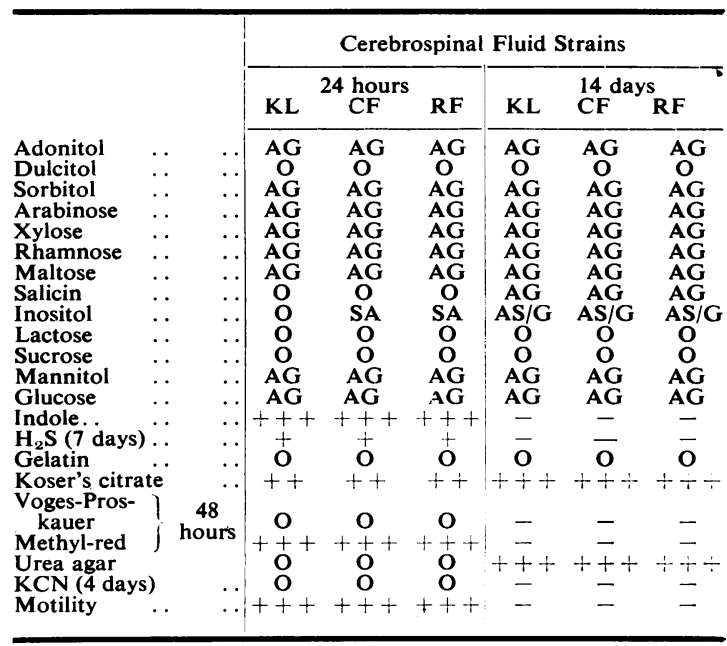

$$
\mathrm{AG}=\text { acid and gas. } \quad \mathrm{O}=\text { no change. } \quad \mathrm{SA}=\text { slight acidity }
$$$$
\mathrm{AS} / \mathrm{G}=\text { acid with small amount of gas. } \quad-=\text { not tested. }
$$

to the strains isolated from the faeces gave the same results. The cultural and biochemical characteristics of the various strains were not identical with those usually associated with typical strains of Esch. coli. They differed in that they fermented adonitol, produced acid and a slight amount of gas in inositol, grew in Koser's citrate medium, produced $\mathrm{H}_{2} \mathrm{~S}$, utilized urea after a period of delay and failed to ferment lactose. The strains from the cerebrospinal fluid and faeces of the first case were submitted to Dr. P. R. Edwards and Dr. Ewing of the 
TABLE 2

DETAILS OF TESTS OF THREE CEREBROSPINAL FLUID STRAINS

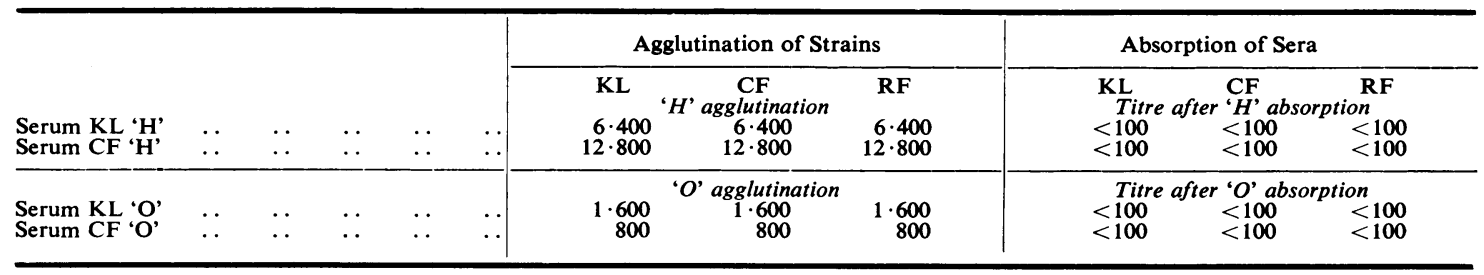

Enteric Disease Centre, Chamblee, Georgia, who reported that the organisms resembled Esch. coli more closely than any other type but were not related to the serological types of Esch. coli 1-137. They were, therefore, classified as intermediate coliforms. Since the cultural and fermentation reactions of all three cerebrospinal fluid and all three faecal strains were identical, ' $\mathrm{H}$ ' and ' $\mathrm{O}$ ' antigens were prepared from the K.L. and C.F. cerebrospinal fluid strains, and four rabbits were immunized. When the agglutinin titre in each animal's serum was sufficiently high, it was bled and the serum preserved with $50 \%$ glycerine. When all four sera were collected, agglutination and agglutinin absorption tests were carried out with the respective ' $\mathrm{H}$ ' and ' $\mathrm{O}$ ' antigens of all three strains isolated from the cerebrospinal fluid and of all three strains isolated from the faeces. The details of the tests for the three cerebrospinal fluid strains are given in Table 2 and show that they are serologically identical. As the strains obtained from the faeces gave similar serological reactions, these results are omitted.

As stated above, Ewing could find no serological relationship with any of the Esch.coli types 1-137. Further tests with polyvalent Salmonella and dysentery sera also failed to show any relationship with these groups of organisms. As a further confirmation of the identity of the strains isolated from the cerebrospinal fluids, their sensitivity to various antibiotics was examined. The method employed was to use the Sentest antibiotic discs prepared by Evans Medical Products, each antibiotic with the exception of bacitracin being tested in two concentrations. The results were recorded according to the approximate degree of inhibition and are given in Table 3. All three strains reacted in a more or less similar manner to 11 antibiotics, being most sensitive to chloramphenicol, neomycin and streptomycin, and less sensitive to the tetracyclines. They were insensitive to erythromycin, novobiocin, oleandomycin and penicillin.

After the second and third cases had occurred the question of the method of spread was considered. Accordingly specimens of faeces were obtained on two occasions from five nurses, four ward maids and two mothers, one being the mother of the affected twins. The nurses and maids might have had contact with the first case as well as the second and third, but the mothers could have had no contact with the first infection which occurred. None of the specimens showed the nonlactose fermenting organism so the actual source of infection was not determined. Furthermore, since the incidents occurred, all non-lactose fermenting and indole positive organisms isolated from specimens of faeces have been tested serologically with the sera prepared, but no further strains have been encountered.

\section{Discussion}

The organism isolated from the three cases was an unusual cause of meningitis. It was a non-lactose fermenting type which had fermentation and biochemical characteristics suggesting a variant of Esch. coli. The fact that it did not ferment lactose enabled it to be isolated from the faeces of the three cases as well as from the cerebrospinal fluids. Apparently it appears infrequently in faeces because, since the incident, some 1,500 specimens of faeces submitted for routine bacteriological investigation

TABLE 3

SENSITIVITY OF STRAINS TO TWO CONCENTRATIONS OF ANTIBIOTICS IN FORM OF SENTESTS

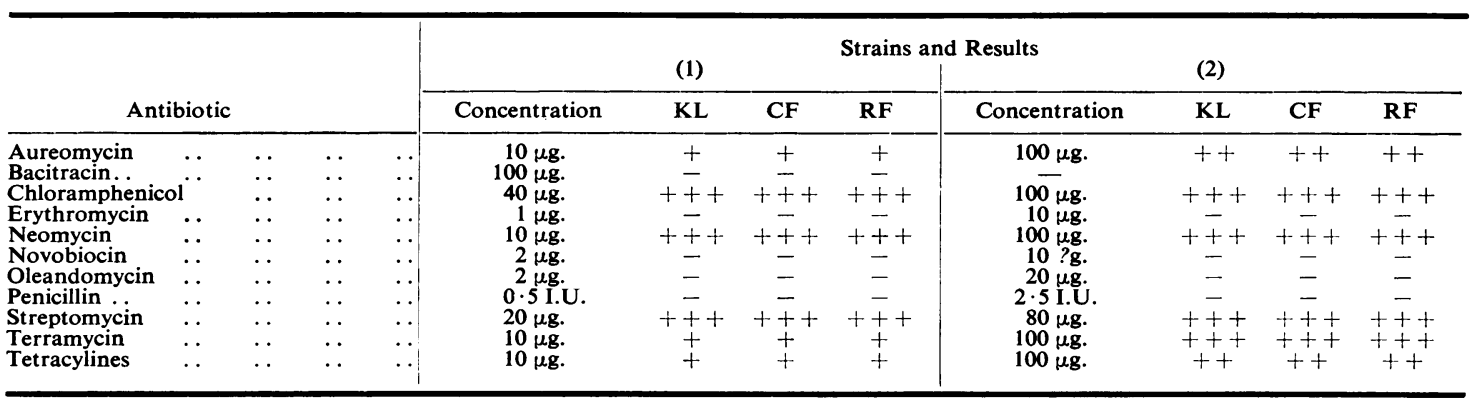


have failed to show its presence. Presumably the organism must have been distributed through the agency of a carrier, for practically a month elapsed between the occurrence of the first case and the second and third. The investigation for such a carrier, however, gave entirely negative results. Presumably also the infants ingested the infecting organism, then developed a bacteraemia, and a subsequent meningitis.

Among the many types of Salmonellae a comparatively small number have been found to be responsible for most cases of spread to the meninges. The same may well be true of other members of the enterobacteriaceae although proof of this is at present lacking. In the majority of reports of this condition the organism is recorded as Esch. coli or paracolon bacillus without details of fermentation or serological reactions. Complete bacteriological data should if possible be given in future reports of such cases so that an answer can be found to this problem.

\section{Summary}

Three cases are recorded of neonatal meningitis occurring in a maternity hospital and due to a previously unidentified non-lactose fermenting member of the enterobacteriaceae.

We are grateful to Professor John Craig for permission to publish these cases, to Dr. N. S. Clark for advice and criticism, and to Dr. A. Sutherland for information and laboratory specimens from the maternity unit involved.

\section{REFERENCES} Barrett, G. S., Rammelkamp, C. H. and Worcester, J. (1942). Amer.

Cooke, J. V. and Bell, H. H. (1922). Ibid., 24, 387.

Henderson, L. L. (1948). Ibid., 75, 351. 